\title{
Interpeduncular Basilar Aneurysm Causing Progressive Locked-In Syndrome: To Coil or Not to Coil
}

\author{
Saud I. Khan William Beaujon Elliott D. Ross \\ Department of Neurology, University of Oklahoma Health Sciences Center, Oklahoma City, Okla., USA
}

Dear Sir,

We describe a patient with progressive locked-in syndrome due to a giant interpeduncular basilar aneurysm that initially underwent coiling and eventually clipping. The case is unusual because the locked-in syndrome was caused by severe midbrain compression rather than an ischemic infarction of the basis pontis, had a gradual rather than abrupt onset and was accompanied by vertical rather than horizontal gaze palsy. Some improvement occurred after the neck of the aneurysm underwent surgical clipping. Based on this case and a review of the literature, we suggest that patients with giant aneurysms in critical locations be treated initially with surgical clipping rather than coiling.

\section{Case Report}

In April of 2002, a 43-year-old woman presented to our institution with sudden onset of severe headache. She was found to have a subarachnoid hemorrhage due to a $2.5-\mathrm{cm}$ interpeduncular giant aneurysm involving the tip of the basilar artery (fig. 1). The neck of the aneurysm was smaller than the dome. The aneurysm was deemed inoperable and was treated with Guglielmi electrolytically detachable coils.
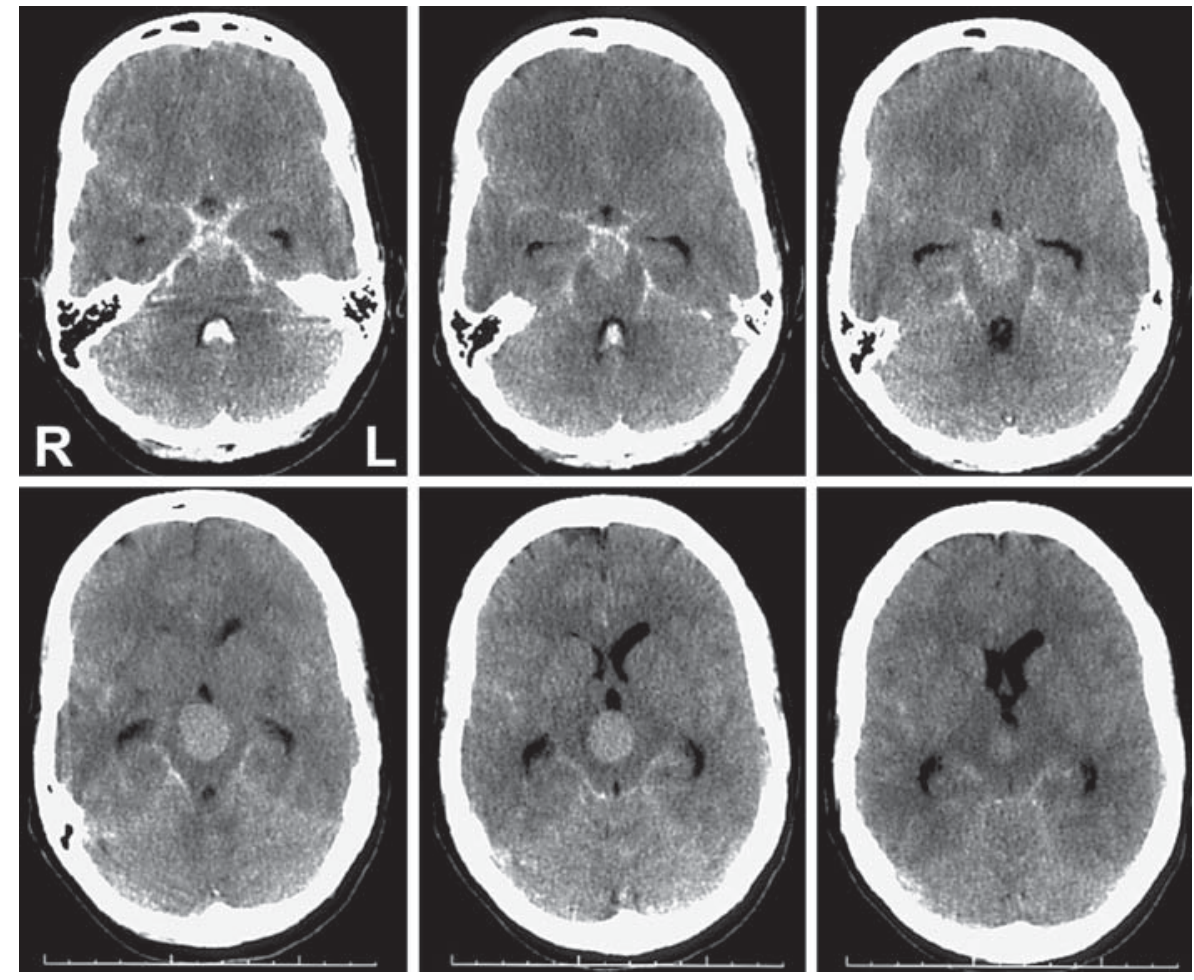

Fig. 1. Noncontrast CT scan when the patient presented with a subarachnoid hemorrhage; the aneurysm can be seen on all six cuts as a hyperintense mass located in the interpeduncular space; blood is present in the basal cisterns and fourth ventricle.

\section{KARGER}

Fax +41613061234

E-Mail karger@karger.ch

www.karger.com
(C) 2008 S. Karger AG, Basel

$0014-3022 / 08 / 0603-0159 \$ 24.50 / 0$

Accessible online at:

www.karger.com/ene
Elliott Ross, MD

Department of Neurology, University of Oklahoma Health Sciences Center

911 S.L. Young Boulevard, Suite 215

Oklahoma City, OK 73104 (USA)

Tel. +1 011405271 4113, Fax +1 011405290 1665, E-Mail elliott-ross@ouhsc.edu 
A postcoiling angiogram showed complete packing of the aneurysm. Her only residual deficit was slowness in communication skills and mild problems with coordination at her right side, attributable to a small infarction involving the left thalamus (fig. 2). Over the next 2 years she remained neurologically stable; both the patient and her husband thought she had been 'cured'. She then began to experience mild urinary retention and complained of an 'antsy feeling' in her legs. These symptoms were evaluated but not attributed to the aneurysm. She then had progressive onset of spastic gait over a month, which was evaluated at a number of hospitals in Oklahoma City and for which she ultimately received gait rehabilitation. During rehabilitation her symptoms seemed to stabilize, but 1 month after discharge she became unable to feed herself because of the gradual onset of upper extremity weakness. A month later she began to lose speech and the ability to swallow with a subsequent bout of aspiration pneumonia. When she finally re-presented at our institution, she was quadriplegic except for minimal movement of her right hand.

On examination, she was awake and able to answer simple yes/no questions by blinking her eyes either once or twice. She was aware of her condition and was oriented. No visual field deficits were observed. She could not swallow or articulate. Her eye movements were conjugate but slow and incomplete, limited to the horizontal plane. The left pupil was $5 \mathrm{~mm}$ with a sluggish reaction to light and the right pupil was $3 \mathrm{~mm}$ with a brisk reaction to light. Occasionally, she could generate a feeble smile. She had a spastic quadriplegia with hyperreflexia, ankle clonus and bilateral Babinski signs. There was minimal ability to contract her right fingers. She was able to feel touch and pain over her face, torso and extremities and she had intact sleep-wake cycles. Her presentation was consistent with a locked-in syndrome and a partial tectal syndrome, indicating a mesencephalic localization.

An MRI scan of the head demonstrated a large, partially coiled aneurysm located just above the basis pontis in the interpeduncular space (fig. 2) that severely compressed the peduncles, tegmentum and tectal regions of the midbrain. The cerebral aqueduct, however, was patent and only minimal enlargement of the third and lateral ventricles was observed. There was an old small left thalamic infarction.
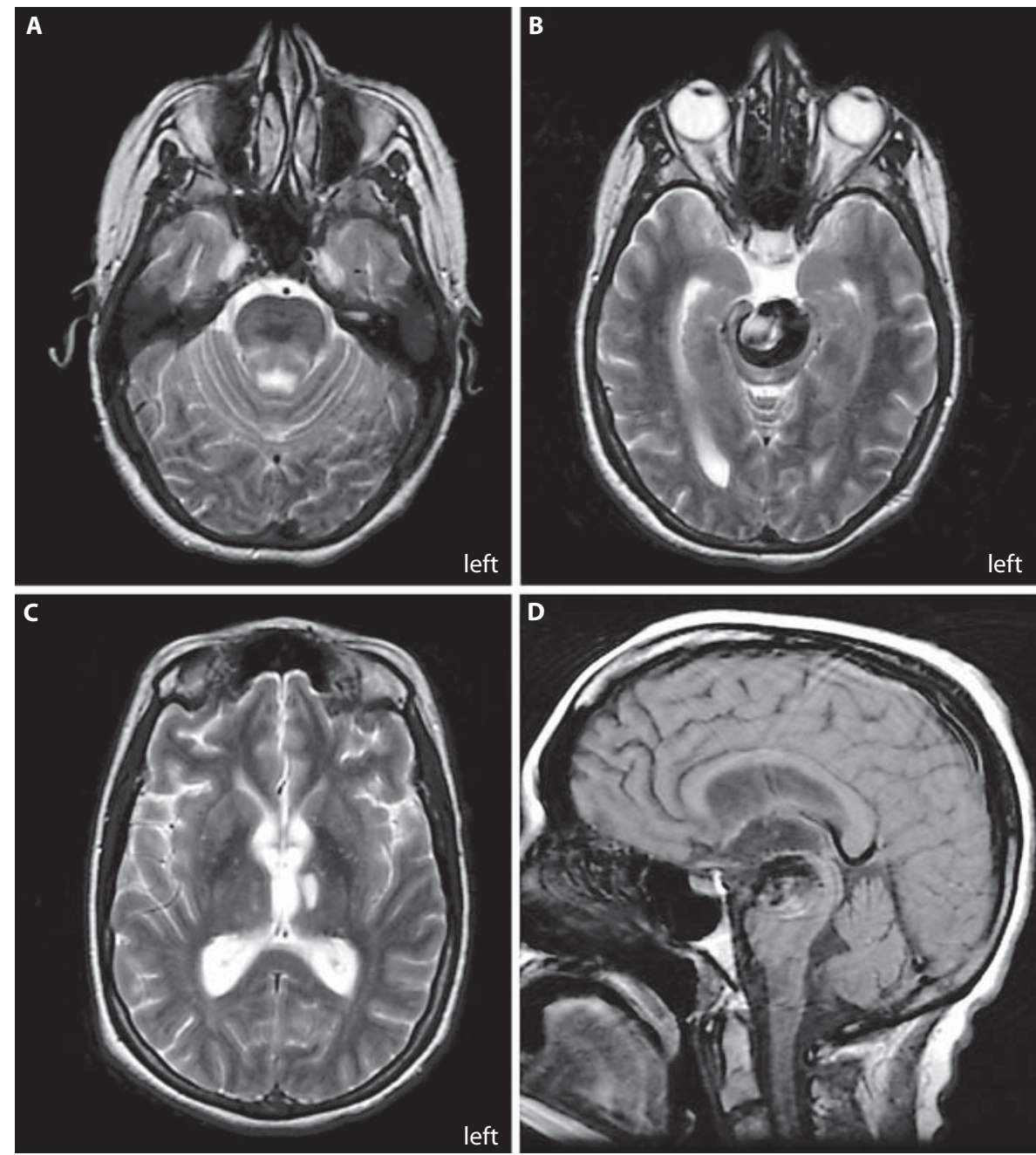

Fig. 2. MRI scan when the patient presented with locked-in syndrome. A $T_{2}$ FSE cut at the level of the rostral pons showing no mass lesion. $\mathbf{B} \mathrm{T}_{2}$ FSE cut at the mid-mesencephalon displaying the aneurysmal mass severely compressing the peduncles, tegmentum and tectum but not obstructing the cerebral aqueduct; within the mass, the dark area indicates blood flow and the light area is the coiled portion. $\mathrm{C} \mathrm{T}_{2}$ FSE cut at the level of the mid-thalamus showing the old left thalamic infarct and minimal enlargement of the third ventricle. D Midsagittal $\mathrm{T}_{1}$ cut demonstrating that the aneurysmal mass does not involve the basis pontis.

Some signal changes were observed in the cerebral peduncles, but no overt infarction was appreciated. Flow artifact was detected at the level of the aneurysm on both the transaxial and sagittal cuts. A fourvessel cerebral angiogram showed flow into the left lateral aspect of the aneurysm, causing enlargement of the previously coiled section that contributed to further expansion of the mass within the interpeduncular space. After consulting with interventional radiology, it was decided that further coiling was not a viable option.

The patient was referred to a center specializing in base of the skull surgery for neurosurgical treatment. The aneurysm was approached through a right temporoparietal craniotomy combined with a right orbito-zygomatic osteotomy. Proximal control of the aneurysm was accomplished by clipping the neck just below the takeoff of 
the superior cerebellar arteries and the aneurysm was reconstructed using two titanium clips. An intraoperative angiogram verified that the aneurysm had been obliterated. Postoperatively, she suffered a complete left-sided third nerve palsy and hydrocephalus that required transient placement of a left ventriculoperitoneal shunt. A slight, 1-mm reduction of the aneurysmal masses was observed on MRI scan. Over 6 months, her left third nerve palsy resolved and she regained some ability to move her right fingers and hand and left foot. She also began to spontaneously articulate short phrases and respond to questions. Her last MRI scan did not demonstrate any new ischemic lesions and there was slight further reduction of the aneurysmal mass.

\section{Discussion}

Locked-in syndrome is characterized classically by quadriplegia, aphonia and horizontal gaze impairment. Because the mesencephalon is usually not affected, patients are conscious and retain the ability to move their eyes vertically and blink. The syndrome is most often due to a basis pontis infarction that damages the corticospinal, corticobulbar and corticopontine tracts bilaterally $[1,2]$. The horizontal gaze palsy is caused by involvement of the fascicles of the abducent nerves. Rarely, it may be due to a brainstem tumor [3] or bilateral midbrain infarcts $[4,5]$.

Our case was unusual because the onset of the locked-in syndrome was progressive, in contrast to the acute onset associated with thrombotic-ischemic events.
The delayed development of symptoms was due to an expanding basilar artery aneurysm that produced a mass effect, compressing the mesencephalon and its peduncles. The loss of conjugate vertical gaze was most likely due to pressure involving the tectum. In reviewing the literature, there are 2 reported cases of locked-in syndrome from a vascular mass effect $[6,7]$. The first was attributed to a dolichoectatic left vertebral artery compressing the ventral medulla [6] and the other was caused by a megadolicho malformation of the basilar artery [7]. A megadolicho basilar artery can also cause cranial nerve and brainstem dysfunction or signs suggesting a posterior fossa space-occupying lesion [8].

Coiling of aneurysms is considered a stable process with a low complication rate of $3.7 \%$ [9]. However, there is a high rate of incomplete obliteration (46\%) and also an increased risk of new aneurysmal formation associated with giant aneurysms [911]. Patients with multiple intracranial aneurysms may be particularly susceptible to new aneurysm formation [10]. In our patient, the coil mass was pushed to the left by the development of a daughter aneurysm that ultimately caused enough compression of mesencephalic structures to produce a locked-in syndrome. Because of the high risk of recurrence of aneursymal dilation after coil embolization of giant aneurysms [9-11], it might be best to send patients with large, normally inoperable, aneurysms in critical locations to specialty neurosurgical centers that have expertise in base of the skull surgery for clipping rather than proceeding with coil embolization.

\section{References}

-1 Bauer G, Gerstenbrand F, Rumpl E: Varieties of the locked-in syndrome. J Neurol 1979; 221:77-91.

-2 Dehaene J, Martin JJ: 'Locked-in' syndrome: a clinico-pathological study of two cases. Eur Neurol 1976;14:81-89.

3 Cherington M, Stears J, Hodges J: Locked-in syndrome caused by tumor. Neurology 1976; 26:180-182.

4 Karp JS, Hurtig L: 'Locked-in' state with bilateral midbrain infarcts. Arch Neurol 1974; 30:176-178.

5 Aoki T, Saiki M, Ishizaki R, Sato T: A case report of bilateral cerebral peduncular infarction manifesting tetraparesis and pseudobulbar palsy (in Japanese). No To Shinkei 2004;56:575-578.

6 Maruyama K, Tanaka M, Ikeda S, Tada T, Yanagisawa N: A case report of quadriparesis due to compression of the medulla oblongata by the elongated left vertebral artery. Rinsho Shinkeigaku 1989;29:108-111.

7 Schoenmaker RT: Locked-in syndrome caused by a megadolicho vascular malformation of the basilar artery. Clin Neurol Neurosurg 1984;86:159-162.

$>8$ Herpers M, Lodder J, Janevski B, van der Lugt PJ: The symptomatology of megadolicho basilar artery. Clin Neurol Neurosurg 1983;85:203-212.

-9 Brilstra EH, Rinkel GJ, van der Graaf Y, van Rooij WJ, Algra A: Treatment of intracranial aneurysms by embolization with coils: a systematic review. Stroke 1999;30:470-476.

10 David CA, Vishteh AG, Spetzler RF, Lemole M, Lawton MT, Partovi S: Late angiographic follow-up review of surgically treated aneurysms. J Neurosurg 1999;91:396-401.

11 Raps EC, Rogers JD, Galetta SL, Solomon RA, Lennihan L, Klebanoff LM, Fink ME: The clinical spectrum of unruptured intracranial aneurysms. Arch Neurol 1993;50: 265-268. 